\title{
LFA-1 and ICAM-1 expression induced during melanoma-endothelial cell co-culture favors the transendothelial migration of melanoma cell lines in vitro
}

\author{
Stephanie Ghislin", Dorian Obino', Sandrine Middendorp', Nicole Boggetto², Catherine Alcaide-Loridan \\ and Frederique Deshayes ${ }^{1,3^{*}}$
}

\begin{abstract}
Background: Patients with metastatic melanoma have a poor median rate of survival. It is therefore necessary to increase our knowledge about melanoma cell dissemination which includes extravasation, where cancer cells cross the endothelial barrier. Extravasation is well understood during travelling of white blood cells, and involves integrins such as LFA-1 (composed of two chains, CD11a and CD18) expressed by T cells, while ICAM-1 is induced during inflammation by endothelial cells. Although melanoma cell lines cross endothelial cell barriers, they do not express LFA-1. We therefore hypothesized that melanoma-endothelial cell co-culture might induce the LFA-1/ICAM ligand/ receptor couple during melanoma transmigration.
\end{abstract}

Methods: A transwell approach has been used as well as blocking antibodies against CD11a, CD18 and ICAM-1. Data were analyzed with an epifluorescence microscope. Fluorescence intensity was quantified with the ImageJ software.

Results: We show here that HUVEC-conditioned medium induce cell-surface expression of LFA-1 on melanoma cell lines. Similarly melanoma-conditioned medium activates ICAM-1 expression in endothelial cells. Accordingly blocking antibodies of ICAM-1, CD11a or CD18 strongly decrease melanoma transmigration. We therefore demonstrate that melanoma cells can cross endothelial monolayers in vitro due to the induction of ICAM-1 and LFA-1 occurring during the co-culture of melanoma and endothelial cells. Our data further suggest a role of LFA-1 and ICAM-1 in the formation of melanoma cell clumps enhancing tumor cell transmigration.

Conclusion: Melanoma-endothelial cell co-culture induces LFA-1 and ICAM-1 expression, thereby favoring in vitro melanoma trans-migration.

Keywords: Melanoma, Transendothelial migration, Metastasis, LFA-1, ICAM-1, HUVEC

\section{Background}

Metastatic melanoma account for most skin cancer deaths. When diagnosed early, primary, non-disseminated, tumors are successfully eliminated through excision. However, in about $20 \%$ of the cases, dissemination of tumor cells leads to aggressive forms of cancers highly refractory

\footnotetext{
* Correspondence: deshayes.frederique@ijm.univ-paris-diderot.fr

${ }^{1}$ Team « Regulation des Reponses Immunitaires ». Institut Jacques Monod, CNRS, UMR 7592, Univ Paris Diderot, Sorbonne Paris Cité, Paris F-75205, France

${ }^{3}$ Equipe : « Regulation des Reponses Immunitaires», INSTITUT JACQUES MONOD, CNRS-Université Paris Diderot, Bâtiment Buffon. 15 rue Hélène Brion, Paris 75205 PARIS CEDEX 13, France

Full list of author information is available at the end of the article
}

to chemotherapy, with a median survival rate of 6 months [1]. Uncovering molecules required for melanoma metastasis is therefore essential.

Hematogenous metastasis of cancer consists of several steps enabling cancer cells to intravasate, to survive in the blood circulation and to adhere to the vessels, eventually extravasating and establishing new metastatic lesions. Extravasation of most cancer cells largely mimics leukocyte transendothelial migration from the blood flow into sites of tissue inflammation [2]. This controlled process involves the multistep action of traffic signals and adhesion molecules that

\section{Biomed Central}


mediate rolling, adhesion and transendothelial migration of lymphocytes [3].

The role of cell adhesion molecules (CAMs), such as intercellular cell adhesion molecule-1 (ICAM-1), vascular endothelial cell adhesion molecule-1 (VCAM-1), E-selectin, and P-selectin, has been studied extensively in the process of inflammation [4]. Indeed, leukocyte adhesion during inflammation is thought to proceed in a cascade-like fashion, in which selectins are responsible for leukocyte capture and rolling, and integrins for mediating firm adhesion and transmigration [5,6]. Among these integrins, Leukocyte Function-Associated antigen-1 (LFA$1 ; \alpha_{\mathrm{L}} \beta_{2}$ ) composed of two chains, CD11a and CD18, has been extensively described for its essential role in leukocyte extravasation [2,7]. It functions as a receptor for ICAM-1 (CD54) [8-10]. Besides its role in the firm adhesion of leukocytes to the endothelium, it appears dominant in transendothelial migration [7,11]. In addition numerous studies have shown that complete inhibition of CD18, or genetic mutations in CD18 profoundly reduce leukocyte transmigration at sites of inflammation [12].

Junctional Adhesion Molecules A (JAM-A) can also interact with LFA-1 via its second membrane-proximal Ig domain $[13,14]$. During leukocyte transendothelial migration, the homophilic transendothelial interactions between two molecules of JAM-A must be disrupted to enable a migrating leukocyte to pass through junctions [15] and it has been evidenced that LFA-1 binding to JAM-A destabilizes the JAM-A homophilic interaction, thus allowing transendothelial migration to proceed [16].

LFA-1 has been studied in different tumors, for instance myelomas and gastrointestinal carcinomas. It has been shown that expression of LFA-1 correlates with the aggressiveness of myeloma [17] and is present in metastatic gastrointestinal carcinomas [18].

In melanoma cell lines, LFA-1 cell-surface expression is not detected. Towards a molecular explanation to the high capacity of melanoma tumor cells to metastase, two groups proposed that melanoma cells interact with neutrophils, thereby suggesting that neutrophils might be used as carriers by the tumor cells [19-21]. Liang et al. [19] have notably demonstrated that under IL-8 signaling, melanoma interact with polymorphonuclear neutrophils (PMNs) through the binding between ICAM-1 on melanoma cells and $\beta_{2}$ integrins on PMNs. The authors also showed that this interaction facilitates melanoma cell adhesion to the endothelial cells and subsequent extravasation by a shear-rate dependent mechanism [21]

However during our studies of melanoma metastasis, we observed that melanoma cell lines have the capacity to transmigrate through endothelial monolayers in the absence of PMNs. We therefore hypothesized that melanoma-endothelial cell co-culture might induce the ICAM-1/LFA-1 ligand-receptor interaction. In this manuscript we studied three human melanoma cell lines with differential transmigration capacities. We provide evidence that melanoma supernatants induce ICAM-1 expression on HUVEC cells, and that LFA-1 can be detected on melanoma cell lines when using HUVEC-conditioned medium. Further confirmation was obtained through the use of either ICAM-1 or LFA-1 blocking antibodies introduced during the coculture and show that they strongly impair melanoma transmigration.

\section{Material and methods}

\section{Cell lines and cell culture}

The melanoma cell line SLM8 kindly provided by M. Viguier (Service de dermatologie, Hopital Saint-Louis, Paris, France), is derived from a lymph node metastasis. The 1205LU cell line, a generous gift by A. Mauviel (Institut Curie/CNRS UMR 3347/Inserm U1021), is derived from the lung metastatic WM793 cell line. The A375 cell line was purchased from the ATCC. HUVEC cells were kindly provided by C. Nahmias (Institut Cochin, Paris, France). A375, 1205LU and SLM8 human cell lines were grown in DMEM/F12 (Invitrogen, CergyPontoise, France) supplemented with antibiotics and $10 \%$ fetal calf serum (FCS) in a 5\% CO2 atmosphere (hereafter named FCS complete medium). HUVEC cells have been cultured in high glucose DMEM containing glutamax, $1 \%$ antibiotics and $10 \%$ FCS in a $5 \% \mathrm{CO} 2$ atmosphere.

\section{Conditioned medium}

To obtain conditioned medium cells were grown to confluence during $48 \mathrm{hrs}$ before collecting the supernatant. The medium was diluted to $3 / 4$ with FCS complete medium (1/4) then added for $24 \mathrm{hrs}$ to the target cells plated at $80 \%$ of confluence. The basal negative control was obtained with only FCS complete medium.

\section{RNA extraction and semi-quantitative PCR}

Total RNA was extracted using the RNeasy kit (Qiagen, Courtaboeuf, France) following the manufacturer's instructions. cDNA was synthesized from $2 \mu \mathrm{g}$ of total RNA using 400 ng oligo(dT) (Invitrogen, Cergy-Pontoise, France), 20 units RNAsin RNase inhibitor (Promega, Madison, Wisconsin, USA) and 8 units Omniscript reverse transcriptase following the manufacturer's instruction. PCR was performed by an initial denaturation step at $95^{\circ} \mathrm{C}$ for $5 \mathrm{~min}$, followed by 30 cycles at $95^{\circ} \mathrm{C}$ for $45 \mathrm{~s}, 60^{\circ} \mathrm{C}$ for $45 \mathrm{~s}$ (GAPDH) and $72^{\circ} \mathrm{C}$ for $1 \mathrm{~min}$. Primer sequences for human GAPDH were: $5^{\prime}$-GTCGTATTGGGCGCCTGGTCAC- $3^{\prime}$ and $5^{\prime}$-AGGGGCCATCCACAGTCTTCTG-3' ${ }^{\prime}$. All primer sequences, hybridization temperature, number of cycles and PCR conditions for other genes tested are summarized in Table 1. 


\section{Flow cytometry}

Cells $\left(5 \times 10^{5}\right)$ treated with conditioned medium from a 48hrs of HUVEC cells culture were harvested in cold phosphate-buffered saline (PBS) containing $1 \mathrm{mM}$ ethylenediaminetetraacetic acid (EDTA) and incubated for 20 min with $2 \%$ fetal calf serum in PBS. Specific direct primary antibodies CD11a antibody (FAB35951A) and CD18 (FAB1730P) from R\&D system (Minneapolis, MN, USA) or isotypic control antibody (BD Pharmingen, San Diego, CA, USA) were used at $1 \mu \mathrm{g} \mathrm{ml}$. After three washes, cell death was monitored by propidium iodide $(5 \mu \mathrm{g} \mathrm{ml})$ uptake and fluorescence was analyzed in a cytometer from DAKO (Trappes, France).

\section{Trans-endothelial migration of melanoma}

Trans-endothelial migration of melanoma was performed as previously described [22]. Briefly, $5 \times 10^{4}$ HUVEC cells were seeded on $2 \mathrm{mg} / \mathrm{ml}$ type I collagen-coated Transwell culture inserts with $8 \mu \mathrm{m}$ pores (Greiner BioOne SAS, Courtaboeuf, France) and grown for 2 days. Melanoma cells were labeled with $10 \mu \mathrm{M}$ of the lipophilic fluorescent dye $\mathrm{DiO}$ (Molecular Probes, Invitrogen, Cergy-Pontoise, France) for 20 minutes at $37^{\circ} \mathrm{C} .5 \times 10^{4}$ fluorescent melanoma cells were added to wells containing either $1 \mu \mathrm{g} / \mathrm{ml}$ of isotypic control (IgG from BD Pharmingen, San Diego, CA, USA); or anti-CD11a (ab3981; Abcam; Paris, France), anti-CD18 (ab8220; Abcam; Paris, France) or anti-ICAM-1 (MAB2146Z; Millipore; Molsheim France) antibodies in the upper chamber. A chemotactic gradient was created by addition of $10 \%$ FCS to the lower chamber. Melanoma cells were allowed to migrate at $37^{\circ} \mathrm{C}$ and $5 \% \mathrm{CO} 2$ for 48 hours.

To remove non-migrating cells, the ones on the upper face of the filter were gently scraped using a cotton swab. Cells on the lower face were washed in PBS, fixed with $4 \%$ formaldehyde for $10 \mathrm{~min}$ and washed in PBS. Nuclei were then labeled with $1 \mu \mathrm{g} / \mathrm{ml}$ DAPI for $5 \mathrm{~min}$ and cells were washed again. The migrating melanoma cells were observed under an epifluorescence microscope using a magnification of $\times 100$. Three to five pictures of adjacent fields of the central zone of each Transwell were taken. Fluorescence intensity was quantified with the Image software (US National Institutes of Health, Bethesda, MD, USA). Histograms display the data obtained with 3 independent experiments, and all the experiments were performed in duplicate. The $p$ value has been calculated by an ANOVA statistical test.

\section{Human cytokine array}

The detection of cytokines' production by the three melanoma cell lines has been tested after 24hrs of culture in $12 \mathrm{ml}$ of culture medium using the Proteome Profiler ${ }^{\text {TM }}$ Array Human Cytokine Array Panel A according to the manufacturer's instructions (ARY005; R\&D systems Minneapolis, USA). Hence, melanoma cells have been tested on nitrocellulose membranes each containing 36 different anti-cytokine antibodies spotted in duplicate. Experiments have been done in duplicate.

\section{Results}

Melanoma cells transmigrate through endothelial cells

Transwell experiments mimicking transendothelial migration were performed with three melanoma cell lines. Briefly, HUVEC cells (Human Umbilical Vein Endothelial Cells) are grown as a monolayer to confluence on a type I collagen matrix layer poured onto a microporous membrane. Melanoma cells, stained with a lipophilic fluorescent dye, are then allowed to cross this barrier for $48 \mathrm{hrs}$. The corresponding membranes of the Transwells are photographed prior to the quantification of fluorescent cancer cells, located at the lower part of the membrane.

As seen in Figure 1, all three cell lines have the capacity to transmigrate. The A375 cell line presents the highest efficiency of transmigration while the SLM8 cell

Table 1 Primer sequences and PCR settings

\begin{tabular}{|c|c|c|c|c|}
\hline Gene name & Primer direction & Sequences $\left(5^{\prime}-3^{\prime}\right)$ & Number of cycle & Hybridization temperature \\
\hline \multirow[t]{2}{*}{ CD11a } & Forward & GGGAATGACCTTGGCAACAGACCCCACAGAT & 34 & 58 \\
\hline & Reverse & GGGTCTCCTGACTCTCCTTGGTCT & & \\
\hline \multirow[t]{2}{*}{ CD18 } & Forward & CATCAGAGCTGCTGTAGAGC & 31 & 60 \\
\hline & Reverse & GCTGACCTTGAACTTCGTGC & & \\
\hline \multirow[t]{2}{*}{ ICAM-1 } & Forward & TGCAGCACCTCCTGTGACCA & 25 & 60 \\
\hline & Reverse & CAGTTCCACCCGTTCTGGAG & & \\
\hline \multirow[t]{2}{*}{ E-Selectin } & Forward & GGACTGCGTGGAGATCTACA & 30 & 61 \\
\hline & Reverse & AGCCAGGGTCACACTTGCAA & & \\
\hline \multirow[t]{2}{*}{$\mathrm{N}$-Cadherin } & Forward & GAAGGATGTGCATGAAGGAC & 30 & 56 \\
\hline & Reverse & AGTTAAGGTTGGCTTCAGGC & & \\
\hline \multirow[t]{2}{*}{ GAPDH } & Forward & GTCGTATTGGGCGCCTGGTCAC & 15 & 60 \\
\hline & Reverse & AGGGGCCATCCACAGTCTTCTG & & \\
\hline
\end{tabular}


line displays the weakest capacity of transendothelial migration. The 1205LU cells have an intermediate phenotype. Interestingly the efficiency of transmigration of these cell lines appeared to correlate with the formation of clumps (Figure 1A). Indeed A375 cells tend to aggregate as clumps whereas the SLM8 cells transmigrate mostly as single cells. 1205 LU cells displayed an intermediate phenotype with a mixture of small clumps and single cells. In order to determine the importance of passive passage of melanoma cell lines, we performed transwell experiments as described below without HUVEC cell monolayer and without chemotactic gradient. In these conditions, the ability of melanoma cells to pass through the microporous membrane was almost inexistent and no significant difference was observed between the three cell lines ( $p$ value $>0.05$ ) (data not shown).

These data indicate that melanoma cells have the capacity in vitro to cross endothelial cell monolayer, although PMNs are not present. We therefore studied the molecular mechanisms leading to this phenomenon.

\section{LFA-1 is involved in melanoma trans-endothelial migration in vitro}

None of the three melanoma cell line expresses the LFA-1 subunits, CD11a or CD18 in classical culture condition (data not shown). However, when cultured in the presence of HUVEC supernatant for 24 hours, all three cell lines display a weak but reproducible expression of both chains at their cell surface (Figure 2).

In order to value the importance of LFA-1 in melanoma transmigration, blocking antibodies specifically directed against CD11a or CD18 were introduced during the transmigration assays. An anti-IgG antibody was used as a negative control. Concerning the two cell lines which transmigrate the most efficiently, A375 and 1205LU, a decrease of their trans-endothelial migration was observed when either CD11a or CD18 blocking antibodies were present (Figure $3 \mathrm{AB}$ ). With the SLM8 cell lines, neither CD18 nor CD11a blocking antibodies affect the transmigration efficiency (Figure 3C).

Melanoma cell lines enhance the expression of ICAM-1 on the HUVEC cells

In normal conditions, HUVEC are known to lack high expression of ICAM-1. However, it has been shown that this level is strongly increased under inflammation [9], as exemplified on Figure 4A, where ICAM-1 transcript expression is highly induced in HUVEC cells treated with $100 \mathrm{ng} / \mathrm{ml}$ of TNF- $\alpha$ and IFN- $\gamma$ (Figure 4A).

As exogenous inflammation molecules are not used in the transmigration assays displayed in this report, we wondered if melanoma cell lines could induce ICAM-1 expression in HUVEC cells. To answer this question,

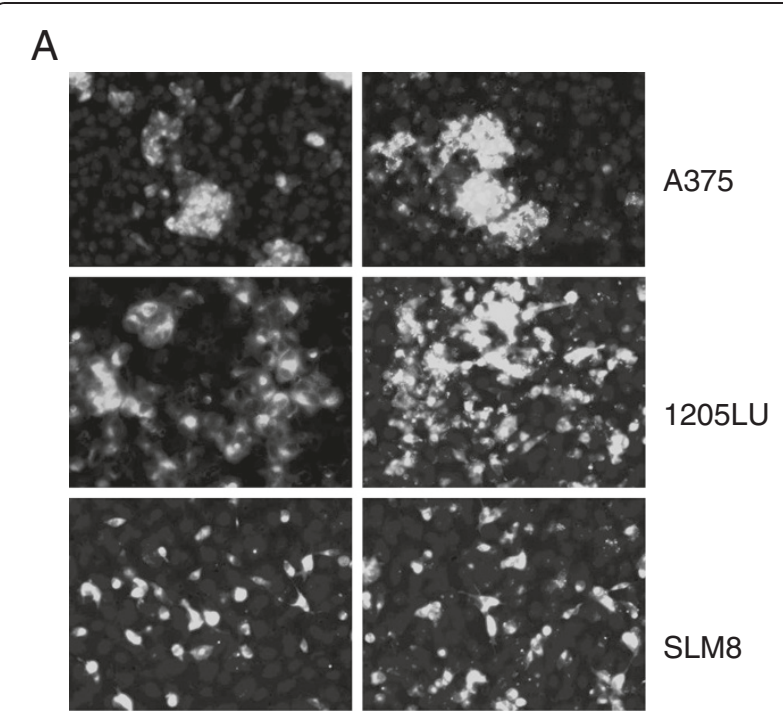

B

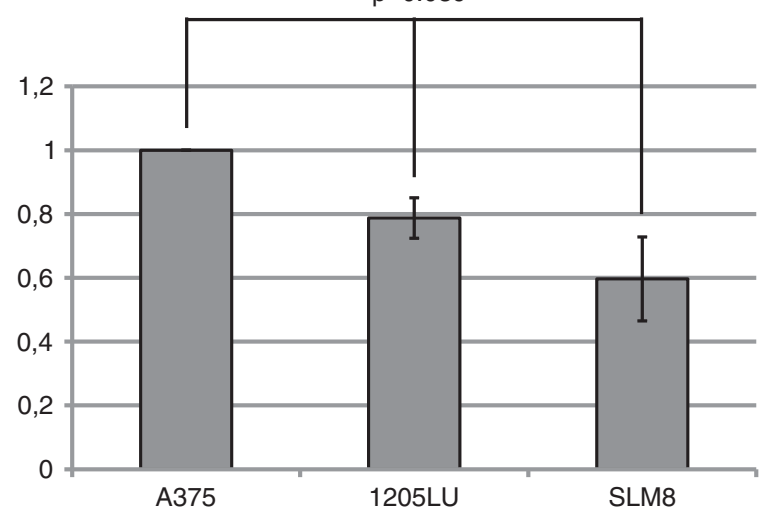

Figure 1 Differential transendothelial migrations of A375, 1205LU and SLM8 cell lines. A HUVEC cells were seeded on type I collagencoated Transwell culture inserts. DiO-labelled melanoma cells were added to the upper chamber and allowed to migrate for $48 \mathrm{~h}$. Cells on the lower face of the inserts were fixed and labeled with DAPI prior to their observation under an epifluorescence microscope. B The histograms represent the quantification of the data obtained from 3 independent experiments, and all the experiments were performed in duplicate. The A375 cell line was considered here as having a $100 \%$ transmigration efficiency.

conditioned medium was prepared from the melanoma cell lines after $48 \mathrm{hrs}$ of culture. The HUVEC cell line was next cultured with this conditioned medium and ICAM-1 transcript expression was analyzed. Figure 4B shows that ICAM-1 is up-regulated by the conditioned medium originating from all three melanoma cell lines, more efficiently with the A375 and 1205LU cell supernatants.

Interestingly, when analyzing the effect of the conditioned medium from melanoma cell lines on different 


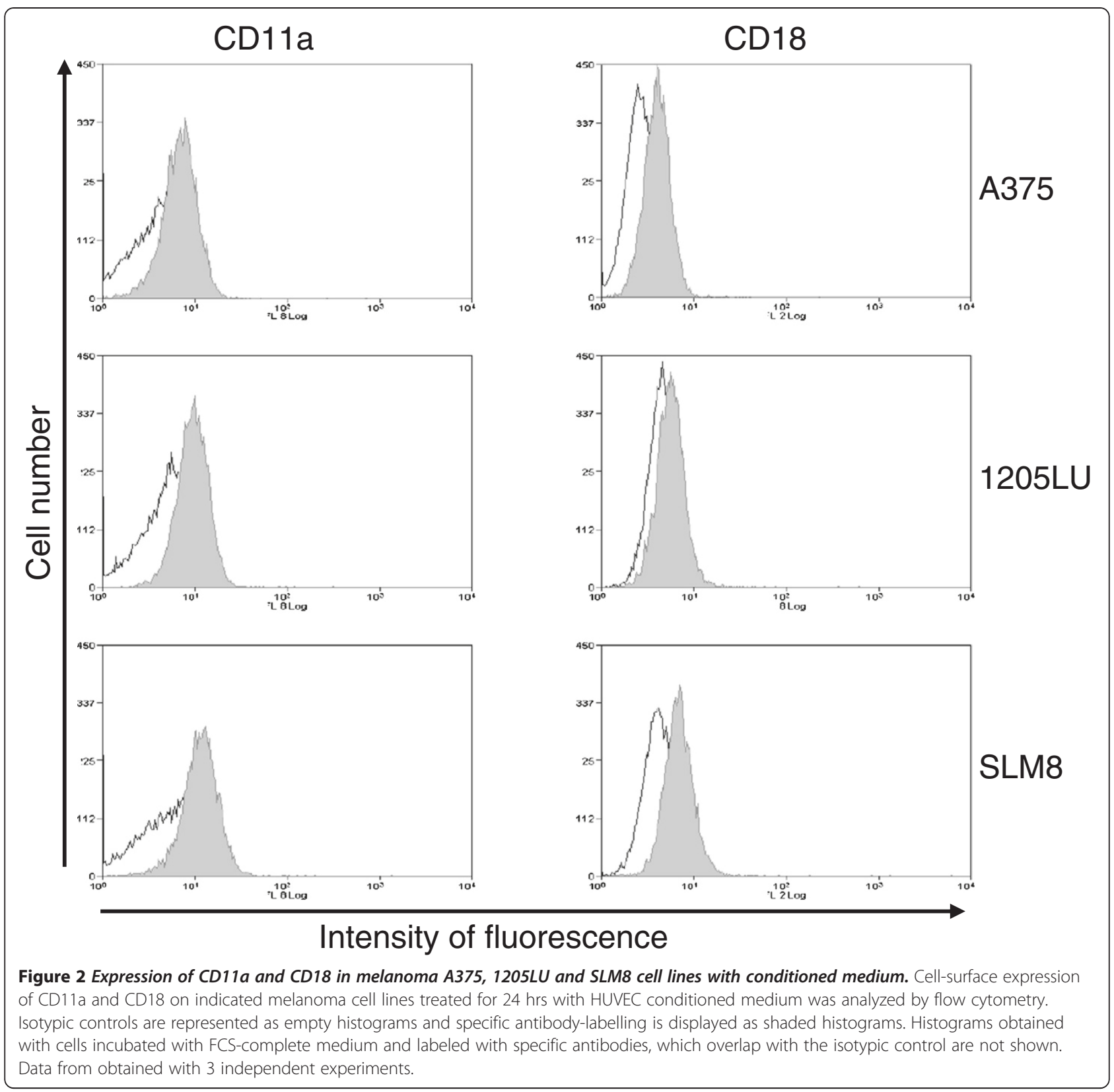

relevant genes, we observed that IL-8 and VEGF were also induced in HUVEC cells (data not shown). However the profile of gene expression was slightly different from the one obtained with IFN- $\gamma$ and TNF- $\alpha$. To identify the cytokines produced by melanoma cells, a cytokine array was next performed (Figure 5). Hence we noticed that melanoma cells, mainly the A375 and 1205LU cell lines, which have the higher capacities of transmigration, secrete pro-inflammatory cytokines, namely GM-CSF and IL-6, which have been described to up-regulate the expression of ICAM-1 [23,24]. In addition all three cell lines secrete molecules such as IL-8 and CXCL-1 (Figure 5). We demonstrated that cells positive for surface expression of ICAM-1 (data not shown) also secrete sICAM-1, which has been extensively published as being up regulated in many tumors [25], notably in melanoma where it has been shown to be associated with disease progression $[26,27]$ and proposed as a prognosis marker [28,29]. Of interest, and to corroborate with our hypothesis, cell lines expressing high amounts of GM-CSF were displaying metastatic competence and invasion [30,31]. 

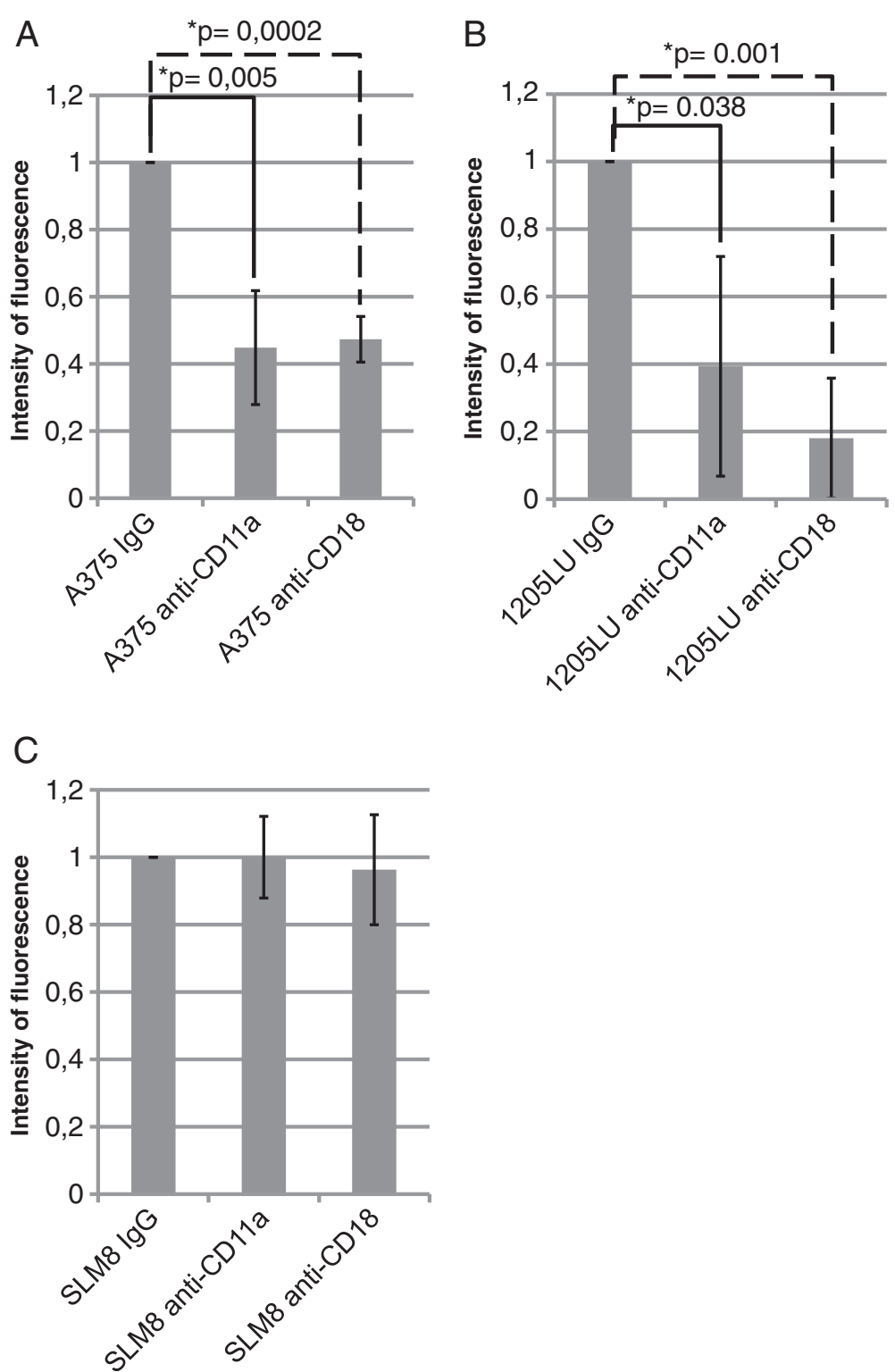

Figure 3 Effect of CD11a and CD18-blocking antibodies on the transendothelial migration of A375, 1205LU and SLM8 cell lines. The experiments were performed as detailed in Figure 1, except that $2 \mu \mathrm{g} / \mathrm{ml}$ of CD11a or CD18-blocking antibodies were introduced in the upper chamber of the Transwells when indicated. Histograms represent 3 independent experiments. In each experiment each condition was analyzed in duplicate.

Indeed the A375 cell line, secreting GM-CSF, has the highest rate of transmigration. Alternatively, one might propose that PAI-1 might be of interest for the 1205LU cell line transmigration, as PAI-1 was reported to affect the degradation of the extracellular matrix [32,33].

Having shown that melanoma cells can induce ICAM-1 expression on HUVEC cells, it was necessary to provide evidence of ICAM-1 implication in the transmigration. ICAM-1 blocking antibodies were assayed on the same cell lines. As seen on Figure 6 blocking ICAM-1 impairs transmigration of A375 and 1205LU, but not that of SLM8, which is consistent with our previous observations of a poor expression of ICAM-1 on endothelial cells when incubated with SLM8-conditioned medium.

We therefore conclude that preferentially the A375 and $1205 \mathrm{LU}$ melanoma cell lines can transmigrate through the endothelial cells due to a binding between ICAM-1 expressed by the HUVEC cells and LFA1expressed by tumor cells during their co-culture. 


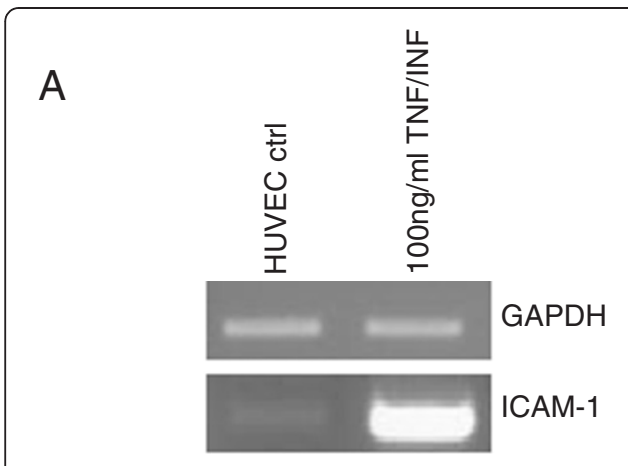

B
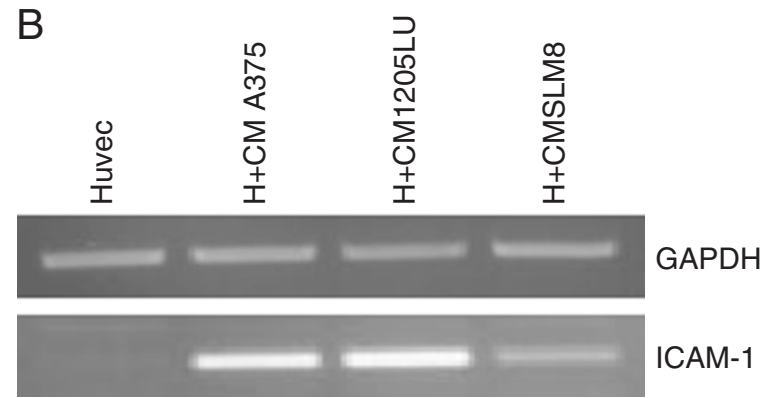

Figure 4 Conditioned mediums from melanoma cell lines enhance transcript expression of ICAM-1 in HUVEC cells. Semi-quantitative PCRs were performed to detect expression of ICAM-1 transcripts. A HUVEC cells were treated either with TNF-a and IFN- $\gamma$ at $100 \mathrm{ng} / \mathrm{ml}$ or B with conditioned medium from A375 (H+A375), SLM8 (H+SLM8) and 1205LU (H+1205LU) after 48hrs of cell culture. GAPDH is used as a DNA amount control. Data were obtained from 3 independent experiments.

\section{LFA-1 is involved in clumps' formation}

As ICAM-1 expression is often detected on melanoma cell lines, we hypothesized that clumps might assemble due to an interaction of LFA-1 and ICAM-1, and that this cell association might enhance melanoma transmigration capacities as described in some tumors [34]. All three melanoma cell lines express ICAM- 1 and LFA- 1 in the presence of conditioned medium from HUVEC cells (Figure 2). However only A375 and 1205LU form cell clumps (Figure 7), suggesting that these sole cell lines possess functional partners for the interaction. To further confirm the role of LFA-1 in the generation of cell clumps, we examined the persistence of clumps by using CD11a and CD18 blocking antibodies. As shown in Figure 7, clump formation is no longer observed when A375 and 1205LU cell lines were treated with anti CD11a and anti CD18. These treatments do not affect the morphology of SLM8 cells. Consequently we propose that transendothelial migration of melanoma would be a cooperating endeavor, with clumps favoring the binding to endothelial cells via the presence of LFA-1 on melanoma cells.
A

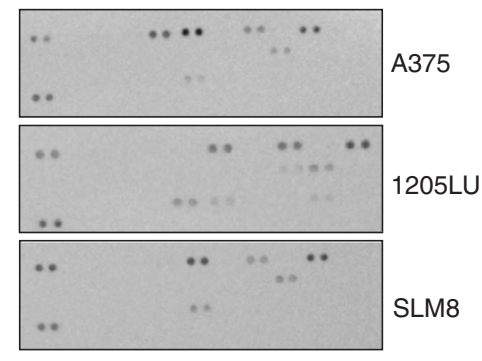

B

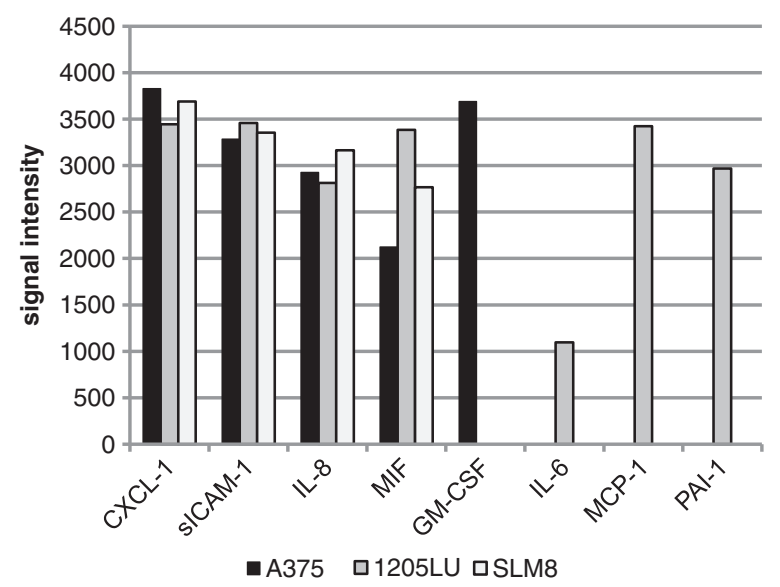

Figure 5 Melanoma cell lines display different cytokine expression profiles. A Melanoma cells were cultured for $24 \mathrm{hrs}$ in $12 \mathrm{ml}$ of DMEM added with $10 \%$ FCS. The supernatant was next tested for the presence of 36 different cytokines. B The histograms represent the quantification by Image J software of the spots obtained on the nitrocellulose membranes. Data were obtained from 2 independent experiments.

\section{Discussion}

The recruitment of lymphocytes to sites of inflammation involves a sequence of rolling along capillary vessel walls, followed by chemokine induced arrest and migration across a tight layer of vascular endothelial cells $[35,36]$. Invasion of tumor cells to secondary sites is often compared with lymphocyte transendothelial migration since several common cell adhesion molecules, such as selectins and integrins, are involved in both lymphocyte and tumor cell migration. It has previously been shown that following secretion of IL-8 in the tumor microenvironment, the PMN facilitated melanoma extravasation via the binding of $\beta 2$ integrins on PMNs and ICAM-1 on melanoma cells [37]. In a congress report, it was mentioned (although not confirmed through a publication) that the co-culture of HUVEC cells and a melanoma cell line from a lymph node metastasis promotes the expression of $\alpha \mathrm{V} \beta 3$ facilitating melanoma extravasation [38]. In this report, we focused 


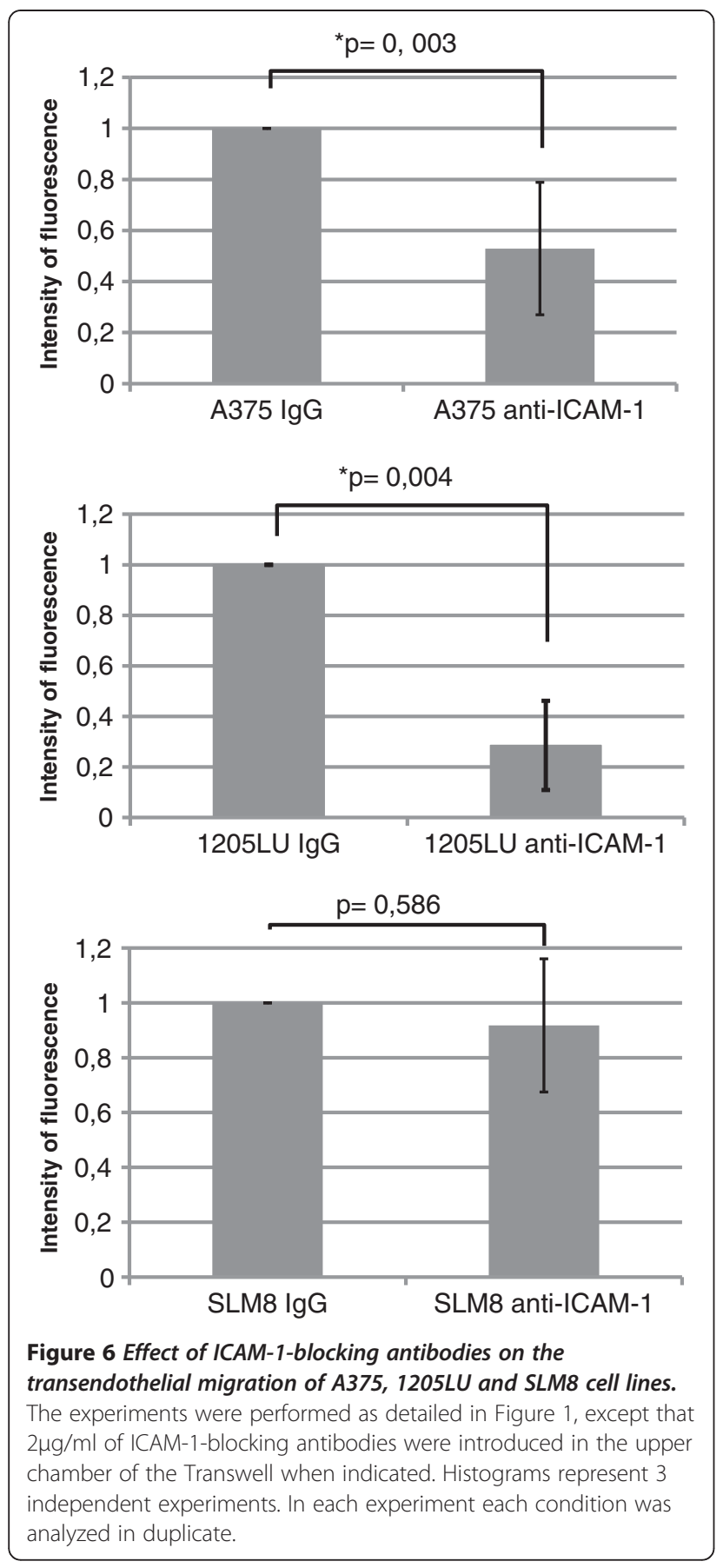

on the direct role of a major integrin, LFA-1 and its counter receptor ICAM-1 in melanoma transmigration. To investigate this hypothesis we used three melanoma cell lines displaying different efficiencies of transendothelial migration but similar expression of the tested integrin. With blocking antibodies against these integrins and ICAM-1, we showed that LFA-1 promotes melanoma cells transmigration in vitro. In addition we provide evidence that LFA-1 seems to be responsible for clumps' formation, which could enhance further their extravasation capacities. This is consistent with previous reports examining the migration of dendritic cells [39] or extravasation of some tumors $[40,41]$.

The expression on melanoma cell lines of such molecules which are normally expressed on immune cells might appear unexpected. However other immune cellspecific molecules have already been shown to be expressed on these tumors. Indeed, we have previously demonstrated that MHCII (major histocompatibility complex, Class II), in contrast with melanocytes, is constitutively expressed on melanoma cells. We have reported that the deregulation of HLA-D genes is due to the abnormal constitutive expression of the lymphocytespecific isoform of class II transactivator (B-CIITA) [42]. This expression is driven by the MAPK cascade [43] and associated with tumour progression and metastatic dissemination [44]. MHCII is not the only immune protein expressed by melanoma cells. Indeed, as exposed above, LFA-1 is able to bind to JAM-A. In a previous publication [22] we provided evidence of the differential roles of JAM proteins, usually expressed by lymphocytes, in melanoma transendothelial migration, where JAM-C promotes their transendothelial migration, while expression of JAM-A inhibits this phenomenon. Although both JAMs are described as adhesion molecules, JAM-A is involved in the tight junctions' maintenance of endothelial cells [45] and it has been reported that LFA-1 binding to JAM-A destabilizes the JAM-A homophilic interaction, thus disrupting this connection, and facilitating its transendothelial migration [16]. Since HUVEC cells express JAM-A (data not shown) this phenomenon could also be, in part, responsible for the transmigration we observed, in conjunction with the interaction between LFA-1 of melanoma cells and ICAM-1 of endothelium and with the formation of melanoma cell clumps (Figure 8), Alternatively an interaction between Mac-1 and ICAM-1 might be relevant, as anti-CD11b antibodies can reduce SLM8 transmigration, while it does not alter the migration of the two other cell lines (data not shown).

Patients with metastatic melanoma have a reduced life span in the range of 6 months. Limited therapeutic treatments explain this poor prognosis. Our findings showing that CD18 blockade impairs melanoma cell transmigration might provide a new tool to control melanoma metastatic mechanism.

\section{Competing of interest}

The authors' declare that they have no competing interests.

\section{Authors' contributions}

SG, DO, CAL and FD designed the study. NG carried out the cytometry analysis. SG, DO, SM and FD performed the data analysis and interpretation. SG, CAL and FD wrote the manuscript. All authors read and approved the final manuscript. 

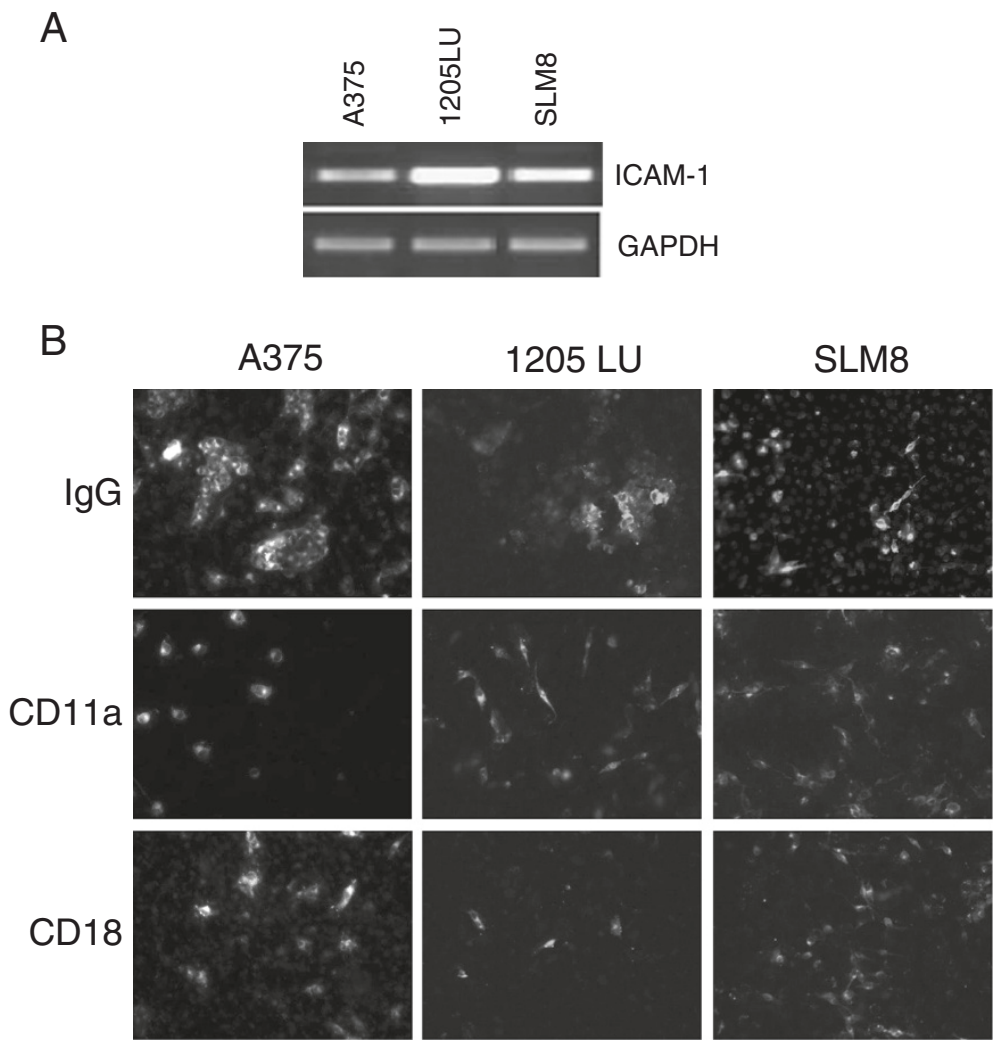

Figure 7 Effect of CD11 and CD18-blocking antibodies on the formation of clumps. A Semi-quantitative PCRs were performed to detect the expression of the ICAM-1 transcript. GAPDH is used as a DNA amount control. B A375, 1205LU and SLM8 cell lines were treated with $2 \mu \mathrm{g} / \mathrm{ml}$ of CD11a or CD18-blocking antibodies as indicated. Melanoma cells were labeled with DiO then fixed and labeled with DAPI prior to their observation under an epifluorescence microscope using a magnification of x10. Data were obtained from 3 independent experiments.

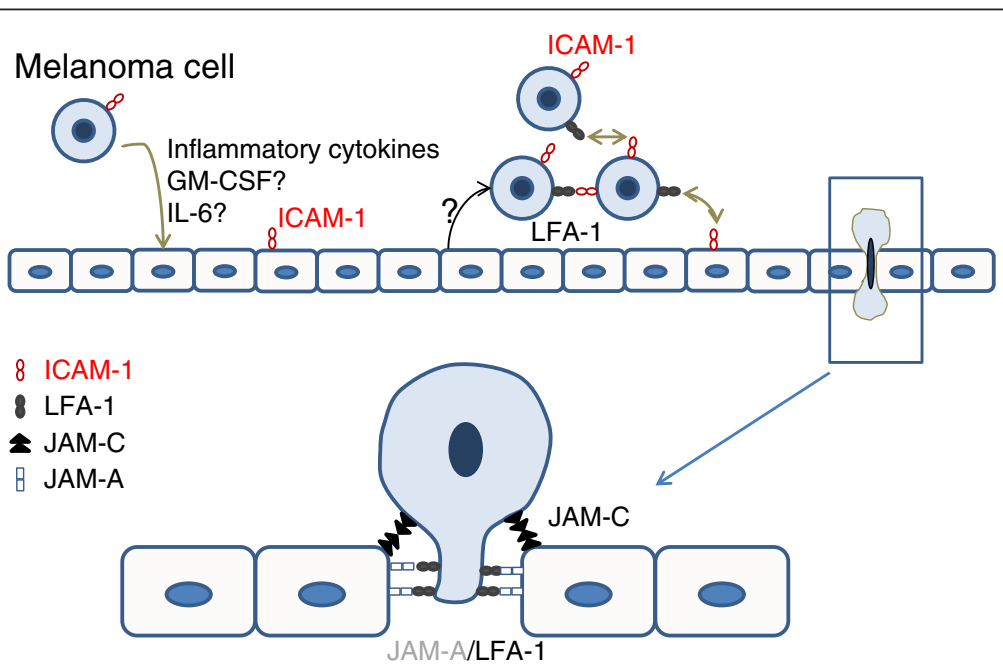

Figure 8 Model of melanoma transmigration. According to these results and to those of our previous publication [22] a model of melanoma transmigration can be proposed involving integrin and JAM proteins. 


\section{Author details}

${ }^{1}$ Team « Regulation des Reponses Immunitaires ». Institut Jacques Monod, CNRS, UMR 7592, Univ Paris Diderot, Sorbonne Paris Cité, Paris F-75205, France. ${ }^{2}$ Imagoseine, plate-forme de cytometrie en flux, Institut Jacques Monod CNRSUniversite Paris Diderot, Paris, France. ${ }^{3}$ Equipe : « Regulation des Reponses Immunitaires», INSTITUT JACQUES MONOD, CNRS-Université Paris Diderot Bâtiment Buffon. 15 rue Hélène Brion, Paris 75205 PARIS CEDEX 13, France

Received: 23 January 2012 Accepted: 1 October 2012

Published: 5 October 2012

\section{References}

1. Bhatia S, Tykodi SS, Thompson JA: Treatment of metastatic melanoma: an overview. Oncology (Williston Park) 2009, 23:488-496

2. Strell C, Entschladen F: Extravasation of leukocytes in comparison to tumor cells. Cell Commun. Signal 2008, 6:10.

3. Springer TA: Traffic signals on endothelium for lymphocyte recirculation and leukocyte emigration. Annu Rev Physiol 1995, 57:827-872.

4. Kobayashi H, Boelte KC, Lin PC: Endothelial cell adhesion molecules and cancer progression. Curr Med Chem 2007, 14:377-386.

5. Butcher EC: Leukocyte-endothelial cell recognition: three (or more) steps to specificity and diversity. Cell 1991, 67:1033-1036.

6. Jung U, Norman KE, Scharffetter-Kochanek K, Beaudet AL, Ley K: Transit time of leukocytes rolling through venules controls cytokine-induced inflammatory cell recruitment in vivo. J Clin Invest 1998, 102:1526-1533.

7. Dunne JL, Ballantyne CM, Beaudet AL, Ley K: Control of leukocyte rolling velocity in TNF-alpha-induced inflammation by LFA-1 and Mac-1. Blood 2002, 99:336-341.

8. Dustin ML, Rothlein R, Bhan AK, Dinarello CA, Springer TA: Induction by IL 1 and interferon-gamma: tissue distribution, biochemistry, and function of a natural adherence molecule (ICAM-1). J Immunol 1986, 137:245-254.

9. Roebuck KA, Finnegan A: Regulation of intercellular adhesion molecule-1 (CD54) gene expression. J Leukoc Biol 1999, 66:876-888.

10. Rothlein R, Dustin ML, Marlin SD, Springer TA: A human intercellular adhesion molecule (ICAM-1) distinct from LFA-1. J Immunol 1986, 137:1270-1274.

11. Ding ZM, Babensee JE, Simon SI, Lu H, Perrard JL, Bullard DC, Dai XY, Bromley SK, Dustin ML, Entman ML, Smith CW, Ballantyne CM: Relative contribution of LFA-1 and Mac-1 to neutrophil adhesion and migration. J Immunol 1999, 163:5029-5038.

12. Arfors KE, Lundberg C, Lindbom L, Lundberg K, Beatty PG, Harlan JM: A monoclonal antibody to the membrane glycoprotein complex CD18 inhibits polymorphonuclear leukocyte accumulation and plasma leakage in vivo. Blood 1987, 69:338-340.

13. Fraemohs L, Koenen RR, Ostermann G, Heinemann B, Weber C: The functional interaction of the beta 2 integrin lymphocyte functionassociated antigen- 1 with junctional adhesion molecule-A is mediated by the I domain. J Immunol 2004, 173:6259-6264.

14. Ostermann G, Weber KSC, Zernecke A, Schröder A, Weber C: JAM-1 is a ligand of the beta(2) integrin LFA-1 involved in transendothelial migration of leukocytes. Nat Immunol 2002, 3:151-158.

15. Williams LA, Martin-Padura I, Dejana E, Hogg N, Simmons DL: Identification and characterisation of human Junctional Adhesion Molecule (JAM). Mol Immunol 1999, 36:1175-1188.

16. Wojcikiewicz EP, Koenen RR, Fraemohs L, Minkiewicz J, Azad H, Weber C, Moy VT: LFA-1 binding destabilizes the JAM-A homophilic interaction during leukocyte transmigration. Biophys J 2009, 96:285-293.

17. Tatsumi T, Shimazaki C, Goto H, Araki S, Sudo Y, Yamagata N, Ashihara E, Inaba T, Fujita N, Nakagawa M: Expression of adhesion molecules on myeloma cells. Jpn J Cancer Res 1996, 87:837-842.

18. Gulubova MV: Expression of cell adhesion molecules, their ligands and tumour necrosis factor alpha in the liver of patients with metastatic gastrointestinal carcinomas. Histochem J 2002, 34:67-77.

19. Liang S, Fu C, Wagner D, Guo H, Zhan D, Dong C, Long M: Twodimensional kinetics of beta 2 -integrin and ICAM-1 bindings between neutrophils and melanoma cells in a shear flow. Am J Physiol Cell Physiol 2008, 294:C743-753.

20. Lynam E, Sklar LA, Taylor AD, Neelamegham S, Edwards BS, Smith CW Simon SI: Beta2-integrins mediate stable adhesion in collisional interactions between neutrophils and ICAM-1-expressing cells. J Leukoc Biol 1998, 64:622-630.
21. Slattery MJ, Dong C: Neutrophils influence melanoma adhesion and migration under flow conditions. Int J Cancer 2003, 106:713-722

22. Ghislin S, Obino D, Middendorp S, Boggetto N, Alcaide-Loridan C, Deshayes F: Junctional adhesion molecules are required for melanoma cell lines transendothelial migration in vitro. Pigment Cell Melanoma Res 2011, 24:504-511.

23. Wung BS, Ni CW, Wang DL: ICAM-1 induction by TNFalpha and IL- 6 is mediated by distinct pathways via Rac in endothelial cells. J Biomed Sci 2005, 12:91-101.

24. Bernasconi S, Matteucci C, Sironi M, Conni M, Colotta F, Mosca M, Colombo N, Bonazzi C, Landoni F, Corbetta G: Effects of granulocytemonocyte colony-stimulating factor (GM-CSF) on expression of adhesion molecules and production of cytokines in blood monocytes and ovarian cancer-associated macrophages. Int J Cancer 1995, 60:300-307.

25. Altomonte M, Colizzi F, Esposito G, Maio M: Circulating intercellular adhesion molecule 1 as a marker of disease progression in cutaneous melanoma. N Engl J Med 1992, 327:959.

26. Harning R, Mainolfi E, Bystryn JC, Henn M, Merluzzi VJ, Rothlein R: Serum levels of circulating intercellular adhesion molecule 1 in human malignant melanoma. Cancer Res 1991, 51:5003-5005.

27. Ciotti P, Imro A, Scudeletti M, Rainero ML, Defferrari R, Ghiorzo P, Indiveri F, Bianchi-Scarrà G: MEL-P, a GM-CSF-producing human melanoma cell line. Melanoma Res 1996, 6:203-213.

28. Alon R, Ley K: Cells on the run: shear-regulated integrin activation in leukocyte rolling and arrest on endothelial cells. Curr Opin Cell Biol 2008 20:525-532.

29. Kohn EC, Hollister GH, DiPersio JD, Wahl S, Liotta LA, Schiffmann E: Granulocyte-macrophage colony-stimulating factor induces human melanoma-cell migration. Int J Cancer 1993, 53:968-972.

30. Burns S, Hardy SJ, Buddle J, Yong KL, Jones GE, Thrasher AJ: Maturation of DC is associated with changes in motile characteristics and adherence. Cell Motil Cytoskeleton 2004, 57:118-132.

31. Hart IR: New evidence for tumour embolism as a mode of metastasis. J Pathol 2009, 219:275-276.

32. Quax PH, van Muijen GN, Weening-Verhoeff EJ, Lund LR, Danø K, Ruiter DJ, Verheijen JH: Metastatic behavior of human melanoma cell lines in nude mice correlates with urokinase-type plasminogen activator, its type-1 inhibitor, and urokinase-mediated matrix degradation. J Cell Biol 1991, 115:191-199.

33. Meissauer A, Kramer MD, Hofmann M, Erkell $L$, Jacob E, Schirrmacher V, Brunner G: Urokinase-type and tissue-type plasminogen activators are essential for in vitro invasion of human melanoma cells. Exp Cell Res 1991, 192:453-459.

34. Min J-K, Kim Y-M, Kim SW, Kwon M-C, Kong Y-Y, Hwang IK, Won MH, Rho J, Kwon Y-G: TNF-related activation-induced cytokine enhances leukocyte adhesiveness: induction of ICAM-1 and VCAM-1 via TNF receptor-associated factor and protein kinase $\mathrm{C}$-dependent NF-kappaB activation in endothelial cells. J Immunol 2005, 175:531-540.

35. Long EO: ICAM-1: getting a grip on leukocyte adhesion. J Immuno/ 2011 186:5021-5023.

36. Friedl P, Gilmour D: Collective cell migration in morphogenesis, regeneration and cancer. Nat Rev Mol Cell Biol 2009, 10:445-457.

37. Liang S, Hoskins M, Dong C: Tumor cell extravasation mediated by leukocyte adhesion is shear rate dependent on IL-8 signaling. Mol Cell Biomech 2010, 7:77-91.

38. Kato Y, Zhang LU, Pili R: Endothelial cells promote metastatic melanoma cell invasion via alpha(v)beta(3) integrin. AACR Meeting Abstracts 2005, 2005:889.

39. Witkowska AM, Borawska MH: Soluble intercellular adhesion molecule-1 (sICAM-1): an overview. Eur Cytokine Netw 2004, 15:91-98.

40. Yamada M, Yanaba K, Takehara K, Sato S: Clinical significance of serum levels of soluble intercellular adhesion molecule-1 and soluble L-selectin in malignant melanoma. Arch Dermatol Res 2005, 297:256-260.

41. Giavazzi R, Foppolo M, Dossi R, Remuzzi A: Rolling and adhesion of human tumor cells on vascular endothelium under physiological flow conditions. J Clin Invest 1993, 92:3038-3044.

42. Baton F, Deruyffelaere C, Chapin M, Prod'homme T, Charron D, Al-Daccak R, Alcaide-Loridan C: Class II transactivator (CIITA) isoform expression and activity in melanoma. Melanoma Res 2004, 14:453-461. 
43. Martins I, Deshayes F, Baton F, Forget A, Ciechomska I, Sylla K, Aoudjit F, Charron D, Al-Daccak R, Alcaide-Loridan C: Pathologic expression of MHC class II is driven by mitogen-activated protein kinases. Eur J Immunol 2007, 37:788-797.

44. Martins I, Sylla K, Deshayes F, Lauriol J, Ghislin S, Dieu-Nosjean M-C, Viguier M, Verola O, Charron D, Alcaide-Loridan C, Al-Daccak R: Coexpression of major histocompatibility complex class II with chemokines and nuclear NFkappaB p50 in melanoma: a rational for their association with poor prognosis. Melanoma Res 2009, 19:226-237.

45. Sargiannidou I, Qiu C, Tuszynski GP: Mechanisms of thrombospondin-1mediated metastasis and angiogenesis. Semin Thromb Hemost 2004, 30:127-136

doi:10.1186/1471-2407-12-455

Cite this article as: Ghislin et al.: LFA-1 and ICAM-1 expression induced during melanoma-endothelial cell co-culture favors the transendothelial migration of melanoma cell lines in vitro. BMC Cancer 2012 12:455.

\section{Submit your next manuscript to BioMed Central and take full advantage of:}

- Convenient online submission

- Thorough peer review

- No space constraints or color figure charges

- Immediate publication on acceptance

- Inclusion in PubMed, CAS, Scopus and Google Scholar

- Research which is freely available for redistribution 